University of New Mexico

UNM Digital Repository

Mathematics and Statistics Faculty and Staff

Publications

Academic Department Resources

$9-2020$

\title{
A novel approach for assessing the reliability of data contained in a single valued neutrosophic number and its application in multiple criteria decision making
}

Florentin Smarandache

Dragisa Stanujkic

Darjan Karabasevic

Gabrijela Popovic

Follow this and additional works at: https://digitalrepository.unm.edu/math_fsp

Part of the Business Administration, Management, and Operations Commons, Business Analytics

Commons, Logic and Foundations Commons, Other Mathematics Commons, and the Set Theory

Commons 


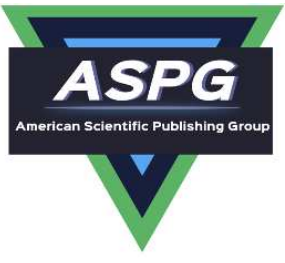

\title{
A Novel Approach for Assessing the Reliability of Data Contained in a Single Valued Neutrosophic Number and its Application in Multiple Criteria Decision Making
}

\author{
Dragisa Stanujkic ${ }^{1}$, Darjan Karabasevic ${ }^{2, *}$, Florentin Smarandache ${ }^{3}$ and Gabrijela Popovic ${ }^{2}$ \\ 1 Technical Faculty in Bor, University of Belgrade, Serbia; dstanujkic@tfbor.bg.ac.rs \\ 2 Faculty of Applied Management, Economics and Finance, University Business Academy in Novi Sad, Belgrade, \\ Serbia; darjan.karabasevic@mef.edu.rs, gabrijela.popovic@mef.edu.rs \\ 3 Dept. Math and Sciences, University of New Mexico, Gallup, NM, USA; smarand@unm.edu
}

* Correspondence: darjan.karabasevic@mef.edu.rs

\begin{abstract}
Multiple criteria decision making is one of the many areas where neutrosophic sets have been successfully applied to solve various problems so far. Compared to a fuzzy set, and similar sets, neutrosophic sets use more membership functions which makes them suitable for using complex evaluation criteria in multiple criteria decision making. On the other hand, the application of three membership functions makes evaluation somewhat more complex compared to evaluation using fuzzy sets. The reliability of the data used to solve a problem can have an impact on the selection of the appropriate solution/alternative. Therefore, this paper discusses an approach that can be used to assess the reliability of information collected by surveying respondents. The usability of the proposed approach is demonstrated in the numerical illustration of the supplier selection.
\end{abstract}

Keywords: neutrosophy, reliability, single-valued neutrosophic numbers, decision-making.

\section{Introduction}

Multiple criteria decision making (MCDM) started to emerge about 50 years ago, and until now it is used for solving a number of different decision-making problems in different fields. MCDM can be defined as making choices in the presence of multiple conflicting criteria [1-3]. Solving complex decision-making problems is usually associated with the need to use a larger number of criteria or use of more complex criteria that are later decomposed into sub-criteria [4-5]. However, an increase in the number of criteria, as well as sub-criteria, can be less desirable in cases where data should be collected by the survey [6].

Significant progress in using the MCDM methods for solving complex decision-making problems was made after Zadeh [7] proposed fuzzy sets, on which basis Bellman and Zadeh [8] proposed fuzzy MCDM [9-10]. Since then, many extensions of fuzzy sets theory have been developed, such as: interval-valued fuzzy sets [11], intuitionistic fuzzy sets [12] and bipolar fuzzy sets [13] . In 1999, Smarandache [14] introduced the concept of neutrosophic sets, as a generalization of the fuzzy sets theory and their extensions. 
So far, neutrosophic sets are successfully used in the area of multi-criteria decision-making. Many extensions of the MCDM methods are proposed based on the use of neutrosophic numbers, such as: neutrosophic AHP [15]; neutrosophic TOPSIS [1]; neutrosophic MULTIMOORA [16]; neutrosophic WASPAS [17]; neutrosophic PROMETHEE [18]; neutrosophic VIKOR [19]; neutrosophic ARAS [20]; neutrosophic GRA [21]; neutrosophic EDAS [22], and so forth. Besides, it is worth mentioning newly-developed approaches, such as: the importance of neutrosophic soft matrices in decision-making [23], interval-valued neutrosophic soft sets in decision-making [24], as well as ivnpiv-neutrosophic soft sets for decision-making [25]. In general, neutrosophy so far is used in solving a number of decision-making problems [26-32].

Fuzzy sets theory introduces partial membership to a set, expressed by membership function $\mu_{(x)}$, where membership function can have different forms, such as: bell-shaped, triangular, trapezoidal and singleton. Some other extensions of fuzzy sets theory introduced other membership functions such as: a non-membership function $v_{(x)}$, a positive membership function $\mu_{(x)}^{+}$and a negative membership function $v_{(x)}^{+}$. Neutrosophic sets theory introduces three membership functions that can be used to describe belonging to a set, that is; truth membership, indeterminacy membership, falsity membership. That is why neutrosophic sets could be more suitable for evaluating complex phenomena, events and problems.

However, the use of three membership functions can make evaluation somewhat more complex compared to evaluation using fuzzy sets. Therefore Smarandache et al. [33] proposed an approach that can be used to assess the reliability of information collected by surveying respondents. This approach is reviewed again in this article, and a new approach for determining the reliability of information contained in single valued neutrosophic numbers is also presented.

Therefore, the remainder of the article is organized as follows: in Section 2 basic elements of neutrosophic sets and single-valued neutrosophic numbers are considered. In Section 3 approaches for ranking single valued neutrosophic numbers are considered, and in Section 4 a numerical illustration is given in order to demonstrate the proposed approach. Finally, conclusions are given.

\section{Basic Elements of Neutrosophic Sets and Single Valued Neutrosophic Numbers}

Definition 1. Let $X$ be a nonempty set, with a generic element in $X$ denoted by $x$. Then, the Neutrosophic Set (NS) $A$ in $X$ is as follows [14]:

$$
A=\left\{\left\langle x, T_{A}(x), I_{A}(x), F_{A}(x)\right\rangle \mid x \in X\right\},
$$

with: $\left.T_{A}: X \rightarrow\right]^{-} 0,1^{+}\left[; I_{A}: X \rightarrow\right]^{-} 0,1^{+}\left[; F_{A}: X \rightarrow\right]^{-} 0,1^{+}\left[\right.$and ${ }^{-} 0 \leq T_{A}(x)+I_{A}(x)+F_{A}(x) \leq 3^{+}$

where: $T_{A}(x), I_{A}(x)$ and $F_{A}(x)$ are the truth-membership function, the indeterminacy-membership function and the falsity-membership function, respectively.

Definition 2. Let $X$ be a nonempty set. The Single Valued Neutrosophic Set (SVNS) $A$ in $X$ is as follows [14, 34]:

$$
A=\left\{\left\langle x, T_{A}(x), I_{A}(x), F_{A}(x)\right\rangle \mid x \in X\right\},
$$

with: $T_{A}: X \rightarrow[0,1] ; I_{A}: X \rightarrow[0,1] ; F_{A}: X \rightarrow[0,1]$ and $0 \leq T_{A}(x)+I_{A}(x)+F_{A}(x) \leq 3$

Definition 3. For an SVNS $A$ in $X$, the triple $<t_{A}, i_{A}, f_{A}>$ is called the Single Valued Neutrosophic Number (SVNN) [14, 34].

Definition 4. Let $X_{i}=<t_{i}, i_{\mathrm{i}}, f_{i}>$ be a collection of SVNNs and $x=<t_{x}, i_{x}, f_{x}>$ a SVNN; then the Hamming distance $h_{(x)}$ between $x$ and the ideal point $x^{+}=<t^{+}, i^{+}, f^{+}>=<\max _{i} t_{i}, \min _{i} i_{i}, \min _{i} f_{i}>$ is as follows: 


$$
h_{(x)}=\frac{1}{3}\left(\left|t^{+}-t_{x}\right|+\left|i^{+}-i_{x}\right|+\left|f^{+}-f_{x}\right|\right) .
$$

Definition 5. Let $A_{j}=<t_{j}, i_{\mathrm{j}}, f_{j}>$ be a collection of SVNNs and $W=\left(w_{1}, w_{2}, \ldots, w_{n}\right)^{T}$ be an associated weighting vector. Then the Single Valued Neutrosophic Weighted Average (SVNWA) operator of $A_{j}$ is as follows [35]:

$$
\operatorname{SVNWA}\left(A_{1}, A_{2}, \ldots, A_{n}\right)=\sum_{j=1}^{n} w_{j} A_{j}=\left(1-\prod_{j=1}^{n}\left(1-t_{j}\right)^{w_{j}}, \prod_{j=1}^{n}\left(i_{j}\right)^{w_{j}}, \prod_{j=1}^{n}\left(f_{j}\right)^{w_{j}}\right)
$$

where: $w_{j}$ is the element $j$ of the weighting vector, $w_{j} \in[0,1]$ and $\sum_{j=1}^{n} w_{j}=1$.

\section{Determining the Reliability of the Information Contained in Single Valued Neutrosophic Numbers}

Smarandache et al. [33] proposed an approach for accessing the reliability of the information $r_{(x)}$ contained in a SVNN, as follows:

$$
r_{(x)}=\frac{t-f}{1+i}
$$

where: $t, i, f$ denote the truth, the intermediacy and the falsity of information contained in SVNN $x=<t, i, f>$, $r \in[-1,1]$.

Example: Assume that $x=<0.9,0.1,0.3>$ is a SVNN. Then, the reliability of $x$ is $r_{(x)}=\frac{0.9-0.3}{1+0.1}=0.55$

In this approach, it is proposed to calculate reliability as follows:

$$
r_{(x)}=\left\{\begin{array}{cc}
\frac{|t-f|}{t+i+f} & t+i+f \neq 0 \\
0 & t+i+f=0
\end{array},\right.
$$

where: $r \in[0,1]$.

Example: Assume that $x=<0.9,0.1,0.3>$ is a SVNN. Then, the reliability of $x$ is $r_{(x)}=\frac{|0.9-0.3|}{0.9+0.1+0.3}=0.46$

One comparison of the reliability calculated using Eq. (5) and Eq. (6) for some characteristic values of $t, i$ and $f$ is shown in Table 1.

Table 1. The reliability calculated using Eq. (5) and Eq. (6)

\begin{tabular}{ccccc}
\hline$t$ & $i$ & $f$ & Eq. (5) & Eq. (6) \\
\hline 1 & 0 & 0 & 1 & 1 \\
0 & 0 & 1 & -1 & 1 \\
1 & 0 & 1 & 0 & 0 \\
1 & 1 & 0 & 0.5 & 0.5 \\
0 & 1 & 1 & -0.5 & 0.5 \\
1 & 1 & 1 & 0 & 0 \\
0 & 0 & 0 & 0 & 0 \\
\hline
\end{tabular}

It can be seen from Table 1, Eq. (5) provides values from the interval [-1, 1], with a value of zero being the least desirable. Equation (6) provides values from the interval $[0,1]$ where a higher value of the reliability function is more desirable. 


\section{A Numerical illustration}

In order to briefly demonstrate the usability of the SVNNs for solving MCDM problems, an example of supplier selection is presented in this section. Assume that one company has to consider engaging with a new supplier. Therefore, a team of three experts if formed with the aim to select the most appropriate supplier from three alternatives, denoted as $A_{1}-A_{3}$, on the basis on the following criteria:

- $C_{1}$ - Delivery,

- $C_{2}-$ Quality,

- $C_{3}-$ Flexibility,

- $C_{4}-$ Service, and

- $C_{5}$ - Price.

The ratings obtained from three experts are shown in Tables 1 to 3.

Table 2. The ratings obtained from the first of three experts

\begin{tabular}{cccccc}
\hline & $C_{1}$ & $C_{2}$ & $C_{3}$ & $C_{4}$ & $C_{5}$ \\
\hline$A_{1}$ & $<0.9,0.10,0.30>$ & $<0.7,0.2,0.3>$ & $<0.6,0.0,0.0>$ & $<0.7,0.0,0.0>$ & $<0.5,0.0,0.1>$ \\
$A_{2}$ & $<0.8,0.00,0.00>$ & $<0.8,0.0,0.1>$ & $<0.8,0.0,0.0>$ & $<0.8,0.0,0.0>$ & $<0.8,0.0,0.0>$ \\
$A_{3}$ & $<0.7,0.00,0.00>$ & $<0.5,0.0,0.0>$ & $<0.6,0.0,0.0>$ & $<0.6,0.0,0.0>$ & $<0.7,0.2,0.0>$ \\
$A_{4}$ & $<0.8,0.10,0.10>$ & $<0.6,0.0,0.0>$ & $<0.7,0.0,0.3>$ & $<0.5,0.2,0.2>$ & $<0.5,0.0,0.0>$ \\
\hline
\end{tabular}

Table 3. The ratings obtained from the second of three experts

\begin{tabular}{cccccc}
\hline & $C_{1}$ & $C_{2}$ & $C_{3}$ & $C_{4}$ & $C_{5}$ \\
\hline$A_{1}$ & $<0.6,0.00,0.10>$ & $<0.7,0.0,0.1>$ & $<0.6,0.0,0.0>$ & $<0.5,0.0,0.0>$ & $<0.2,0.0,0.9>$ \\
$A_{2}$ & $<0.8,0.00,0.30>$ & $<0.6,0.0,0.1>$ & $<0.7,0.0,0.0>$ & $<0.8,0.0,0.2>$ & $<0.1,0.0,0.8>$ \\
$A_{3}$ & $<0.7,0.00,0.30>$ & $<0.8,0.0,0.0>$ & $<0.7,0.0,0.0>$ & $<0.6,0.0,0.4>$ & $<0.3,0.0,0.2>$ \\
$A_{4}$ & $<0.6,0.00,0.20>$ & $<0.7,0.1,0.2>$ & $<0.7,0.0,0.0>$ & $<0.6,0.0,0.4>$ & $<0.5,0.0,0.1>$ \\
\hline
\end{tabular}

Table 4. The ratings obtained from the third of three experts

\begin{tabular}{cccccc}
\hline & $C_{1}$ & $C_{2}$ & $C_{3}$ & $C_{4}$ & $C_{5}$ \\
\hline$A_{1}$ & $<0.8,0.20,0.20>$ & $<0.6,0.0,0.4>$ & $<0.5,0.0,0.0>$ & $<0.6,0.0,0.1>$ & $<0.8,0.0,0.4>$ \\
$A_{2}$ & $<0.6,0.10,0.10>$ & $<0.6,0.2,0.4>$ & $<0.8,0.1,0.0>$ & $<0.5,0.0,0.1>$ & $<0.7,0.0,0.0>$ \\
$A_{3}$ & $<0.6,0.00,0.00>$ & $<0.7,0.0,0.3>$ & $<0.6,0.1,0.0>$ & $<0.6,0.0,0.0>$ & $<0.5,0.1,0.3>$ \\
$A_{4}$ & $<0.7,0.00,0.00>$ & $<0.8,0.0,0.2>$ & $<0.7,0.0,0.0>$ & $<0.6,0.0,0.1>$ & $<0.6,0.0,0.0>$ \\
\hline
\end{tabular}

The reliability of ratings obtained using Eq. (5) and Eq. (6) are shown in Tables 5 and 6. The average reliability of all ratings are also shown in Tables 5 and 6.

Table 5. The reliability of ratings obtained from the first expert using Eq. (5)

\begin{tabular}{cccccc}
\hline & $C_{1}$ & $C_{2}$ & $C_{3}$ & $C_{4}$ & $C_{5}$ \\
\hline$A_{1}$ & 0.55 & 0.33 & 0.60 & 0.70 & 0.40 \\
$A_{2}$ & 0.80 & 0.70 & 0.80 & 0.80 & 0.80 \\
$A_{3}$ & 0.70 & 0.50 & 0.60 & 0.60 & 0.58 \\
$A_{4}$ & 0.64 & 0.60 & 0.40 & 0.25 & 0.50 \\
\hline & & & & $\mathrm{Avg}$ & 0.59 \\
\hline
\end{tabular}

Table 6. The reliability of ratings obtained from the first expert using Eq. (6)

\begin{tabular}{cccccc}
\hline & $C_{1}$ & $C_{2}$ & $C_{3}$ & $C_{4}$ & $C_{5}$ \\
\hline$A_{1}$ & 0.46 & 0.33 & 1.00 & 1.00 & 0.67 \\
$A_{2}$ & 1.00 & 0.78 & 1.00 & 1.00 & 1.00 \\
$A_{3}$ & 1.00 & 1.00 & 1.00 & 1.00 & 0.78 \\
$A_{4}$ & 0.70 & 1.00 & 0.40 & 0.33 & 1.00 \\
\hline \multicolumn{4}{r}{} \\
\hline
\end{tabular}


The average reliability of responses obtained from all three decision makers, calculated using Eq. (6), are accounted for in Table 7.

Table 7. The average reliability of ratings obtained from all experts using Eq. (6)

\begin{tabular}{cc}
\hline & Reliability \\
\hline$E_{1}$ & 0.82 \\
$E_{2}$ & 0.65 \\
$E_{3}$ & 0.69 \\
\hline
\end{tabular}

As can be seen from Table 7, all three experts provide relatively consistent responses, and therefore their ratings can be used for further evaluation of alternatives. In contrast, if the average reliability of ratings obtained from a respondent has low value, his or her responses must be rejected from further evaluation of the alternatives or his or her responses must be re-considered again until adequate reliability is achieved.

A possible scenario of the evaluation of alternatives is discussed below. A group decision matrix, shown in Table 8, is constructed using Eq. (4) and the following weights $w_{j}=\left(\frac{1}{3}, \frac{1}{3}, \frac{1}{3}\right)$. The overall ratings are calculated using Eq. (4) and the following weighting wector $w_{j}=(0.19,0.22,0.19,0.18,0.22)$, as it is shown in Table 9. The ideal point is also shown in Table 9.

Table 8. The group decision matrix

\begin{tabular}{cccccc}
\hline & $C_{1}$ & $C_{2}$ & $C_{3}$ & $C_{4}$ & $C_{5}$ \\
\hline$w_{j}$ & 0.19 & 0.22 & 0.19 & 0.18 & 0.22 \\
\hline$A_{1}$ & $<0.80,0.1,0.20>$ & $<0.67,0.1,0.28>$ & $<0.57,0.0,0.00>$ & $<0.61,0.0,0.03>$ & $<0.57,0.0,0.62>$ \\
$A_{2}$ & $<0.75,0.0,0.14>$ & $<0.68,0.1,0.21>$ & $<0.77,0.0,0.00>$ & $<0.73,0.0,0.10>$ & $<0.62,0.0,0.41>$ \\
$A_{3}$ & $<0.67,0.0,0.11>$ & $<0.69,0.0,0.11>$ & $<0.64,0.0,0.00>$ & $<0.60,0.0,0.16>$ & $<0.53,0.1,0.18>$ \\
$A_{4}$ & $<0.71,0.0,0.10>$ & $<0.71,0.0,0.14>$ & $<0.70,0.0,0.11>$ & $<0.57,0.1,0.24>$ & $<0.54,0.0,0.03>$ \\
\hline
\end{tabular}

Table 9. The overall ratings and ideal point

\begin{tabular}{lc}
\hline & Overall ratings \\
\hline$A_{1}$ & $<0.65,0.00,0.00>$ \\
$A_{2}$ & $<0.71,0.00,0.00>$ \\
$A_{3}$ & $<0.63,0.00,0.00>$ \\
$A_{4}$ & $<0.65,0.00,0.10>$ \\
\hline$A^{+}$ & $<0.71,0.00,0.00>$ \\
\hline
\end{tabular}

Finally, the ranking results, obtained using Eq. (3), are encountered for in Table 10.

Table 10. The ranking results

\begin{tabular}{lcc}
\hline & $h_{(i)}$ & Rank \\
\hline$A_{1}$ & 0.0063 & 2 \\
$A_{2}$ & 0.0000 & 1 \\
$A_{3}$ & 0.0092 & 3 \\
$A_{4}$ & 0.0179 & 4 \\
\hline
\end{tabular}

As can be seen from Table 10, the most appropriate alternative is alternative denoted as $A_{2}$.

\section{Conclusion}

Neutrosophic sets theory introduces three membership functions that is why single-valued neutrosophic numbers could be suitable for evaluating alternatives in relation to the complex evaluation criteria in multiple criteria decision making. However, the use of three membership functions can make evaluation somewhat complex especially when the evaluation is based on data collected by the survey. 
The reliability of the data used to solve a problem can have an impact on the final selection of the appropriate alternative. In this manuscript, an improved procedure for estimating the reliability of the collected data is proposed.

Therefore, Smarandache et al. [33] has proposed an approach that can be used to assess the reliability of information collected by surveying respondents.

Compared to the previous approach, in the new approach reliability and information belong to the interval [0, 1], unlike the previously proposed approach where reliability belongs to the interval [-1, 1], which makes new application easier for using.

By using the proposed procedure, the reliability of data could be easily determined. In this paper, the usability and efficiency of the proposed approach is successfully demonstrated on an illustrative example of the supplier selection.

Funding: The research presented in this article was done with the financial support of the Ministry of Education, Science and Technological Development of the Republic of Serbia, as part of the financing of scientific research at the University of Belgrade, Technical Faculty in Bor.

Conflicts of Interest: "The authors declare no conflict of interest."

\section{References}

1. Karabašević, D., Stanujkić, D., Zavadskas, E. K., Stanimirović, P., Popović, G., Predić, B., \& Ulutaş, A., “A Novel Extension of the TOPSIS Method Adapted for the Use of Single-Valued Neutrosophic Sets and Hamming Distance for E-Commerce Development Strategies Selection”, Symmetry, Vol 12(8), pp. 1263, 2020.

2. Bakir, M., Akan, Ş., Kiraci, K., Karabasevic, D., Stanujkic, D., \& Popovic, G., "Multiple-Criteria Approach of the Operational Performance Evaluation in the Airline Industry: Evidence from the Emerging Markets", Romanian Journal of Economic Forecasting, Vol 23(2), pp. 149-172, 2020.

3. Ivanov, B., Jevtić, M., Stanujkić, D., Karabašević, D., \& Smarandache, F., "Evaluation of websites of IT companies from the perspective of IT beginners", Bizinfo, Vol 9(2), pp. 1-9, 2018.

4. Stanujkic, D., Karabasevic, D., Zavadskas, E. K., Smarandache, F., \& Brauers, W. K., “A bipolar fuzzy extension of the MULTIMOORA method", Informatica, Vol 30(1), pp. 135-152, 2019.

5. Stanujkic, D., Zavadskas, E. K., Liu, S., Karabasevic, D., \& Popovic, G., "Improved OCRA method based on the use of interval grey numbers", Journal of Grey System, Vol 29(4), pp. 49-60, 2017.

6. Pamucar, D., Lukovac, V., Bozanic, D., \& Komazec, N., "Multi-criteria FUCOM-MAIRCA model for the evaluation of level crossings: case study in the Republic of Serbia", Operational Research in Engineering Sciences: Theory and Applications, Vol 1(1), pp. 108-129, 2018.

7. Zadeh, L. A., "Fuzzy sets. Information and control", Vol 8(3), pp. 338-353, 1965.

8. Bellman, R. E., \& Zadeh, L. A., "Decision-making in a fuzzy environment”, Management science, Vol 17(4), pp. 141-164, 1970.

9. Stanujkic, D., Zavadskas, E. K., Karabasevic, D., Urosevic, S., \& Maksimovic, M., “ An approach for evaluating website quality in hotel industry based on triangular intuitionistic fuzzy numbers", Informatica, Vol 28(4), pp. 725-748, 2017.

10. Stanujkić, D., Smarandache, F., Zavadskas, E. K., \& Karabašević, D., "Multiple Criteria Evaluation Model Based on the Single Valued Neutrosophic Set”, Neutrosophic Sets and Systems, Vol 14, pp. 3-6, 2016.

11. Turksen, I. B., "Interval valued fuzzy sets based on normal forms", Fuzzy sets and systems, Vol 20(2), pp. 191$210,1986$.

12. Atanassov, K., "Intuitionistic fuzzy sets”, Fuzzy Sets and Systems, Vol 20, pp. 87-96, 1986.

13. Lee, K.M., "Bipolar-valued fuzzy sets and their operations", Proceedings of International conference on intelligent technologies - InTech'2000, December 12-14, 2000, Bangkok, Thailand, 307-312, 2000.

14. Smarandache, F., "A Unifying Field in Logics. Neutrosophy: Neutrosophic Probability, Set and Logic", American Research Press: Rehoboth, DE, USA. pp. 141, 1999. 
15. Bolturk, E., \& Kahraman, C., “A novel interval-valued neutrosophic AHP with cosine similarity measure” Soft Computing, Vol 22(15), pp. 4941-4958, 2018.

16. Stanujkic, D., Zavadskas, E. K., Smarandache, F., Brauers, W. K., \& Karabasevic, D., "A neutrosophic extension of the MULTIMOORA method", Informatica, Vol 28(1), pp. 181-192, 2017.

17. Bausys, R., Kazakeviciute-Januskeviciene, G., Cavallaro, F., \& Usovaite, A., "Algorithm selection for edge detection in satellite images by neutrosophic WASPAS method", Sustainability, Vol 12(2), pp. 548, 2020.

18. Zavadskas, E. K., Bausys, R., Kaklauskas, A., \& Raslanas, S., "Hedonic shopping rent valuation by one-to-one neuromarketing and neutrosophic PROMETHEE method", Applied Soft Computing, Vol 85, pp. 105832, 2019.

19. Abdel-Basset, M., Zhou, Y., Mohamed, M., \& Chang, V., “A group decision making framework based on neutrosophic VIKOR approach for e-government website evaluation”, Journal of Intelligent \& Fuzzy Systems, Vol 34(6), pp. 4213-4224, 2018.

20. Liu, P., \& Cheng, S., “ An Extension of ARAS Methodology for Multi-criteria Group Decision-Making Problems within Probability Multi-valued Neutrosophic Sets”, International Journal of Fuzzy Systems, Vol 21(8), pp. 2472-2489, 2019.

21. Biswas, P., Pramanik, S., \& Giri, B. C., "GRA method of multiple attribute decision making with single valued neutrosophic hesitant fuzzy set information”, New trends in neutrosophic theory and applications, pp. 55-63, 2016.

22. Karaşan, A., \& Kahraman, C., "A novel interval-valued neutrosophic EDAS method: prioritization of the United Nations national sustainable development goals", Soft Computing, Vol 22(15), pp. 4891-4906, 2018.

23. Deli, I., \& Broumi, S., "Neutrosophic soft matrices and NSM-decision making", Journal of Intelligent \& Fuzzy Systems, Vol 28(5), pp. 2233-2241, 2015.

24. Deli, I., "Interval-valued neutrosophic soft sets and its decision making", International Journal of Machine Learning and Cybernetics, Vol 8(2), pp. 665-676, 2017.

25. Deli, I., Eraslan, S., \& Çağman, N., "ivnpiv-Neutrosophic soft sets and their decision making based on similarity measure", Neural Computing and applications, Vol 29(1), pp. 187-203, 2018.

26. Ashraf, S., \& Abdullah, S., "Decision Support Modeling For Agriculture Land Selection Based On Sine Trigonometric Single Valued Neutrosophic Information", International Journal of Neutrosophic Science (IJNS), Vol 9(2), pp. 60-73, 2020.

27. Martin, N., \& Smarandache, F., "Plithogenic Cognitive Maps in Decision Making", International Journal of Neutrosophic Science (IJNS), Vol 9(1), pp. 9-21, 2020.

28. Edalatpanah, S. A., "A direct model for triangular neutrosophic linear programming”, International journal of neutrosophic science (IJNS), Vol 1(1), pp. 19-28, 2020.

29. Gayathri, N., Helen, M., \& Mounika, P., "Utilization of Jaccard Index Measures on Multiple Attribute Group Decision Making under Neutrosophic Environment”, International Journal of Neutrosophic Science (IJNS), Vol 3(2), pp. 67-77, 2020.

30. Stanujkić, D., Smarandache, F., Zavadskas, E. K., \& Karabašević, D., “An Approach to Measuring the Website Quality Based on Neutrosophic Sets", New Trends in Neutrosophic Theory and Applications, Vol II, pp. 40$50,2017$.

31. Urošević, S., Stanujkić, D., Karabašević, D., \& Brzaković, P., "Using single valued neutrosophic set to select tourism development strategies in eastern Serbia", Economics of Agriculture, Vol 65(2), pp. 555-568, 2018.

32. Ivanov, B., Jevtić, M., Stanujkić, D., \& Karabašević, D., "Evaluation of websites of IT companies from the perspective of it beginners", Bizinfo, Vol 9(2), pp. 1-9, 2018.

33. Smarandache, F., Stanujkic, D. \& Karabasevic, D., "An approach for assessing the reliability of data contained in a single valued neutrosophic number", Proceedings of 4th International scientific conference Innovation as an initiator of the development - MEFkon 2018, 6th December, 2018, Belgrade, Serbia, pp. 80-86, 2018.

34. Wang, H., Smarandache, F., Zhang, Y. Q. \& Sunderraman, R., "Single valued neutrosophic sets", Multispace and Multistructure, Vol 4, pp. 410-413, 2010. 
35. Şahin, R., "Multi-criteria neutrosophic decision making method based on score and accuracy functions under neutrosophic environment", arXiv preprint arXiv:1412.5202, 2014. 